\title{
COMPROMETIMENTO ORGANIZACIONAL: UM ESTUDO COMPARATIVO ENTRE DOCENTES E SERVIDORES DO IFRN-CAMPUS NOVA CRUZ
}

\author{
L. O. ALVES, E. M. AREAÚJJ, F. L. N. B. MELO \\ felipeluizneves@hotmail.com
}

\section{RESUMO}

O comprometimento organizacional tem sido estudado por diversas metodologias nas últimas décadas, porém, a sua compreensão ainda se encontra em fase inicial (MELO et al., 20I4; MEDEIROS, 2003), tornando-se uma temática que desperta o interesse de pesquisadores a abordarem as dimensões do comprometimento organizacional em diversas áreas. Diante da lacuna de estudos que avaliem o comprometimento organizacional em instituições de ensino, o presente estudo teve como objetivo avaliar o comprometimento organizacional dos servidores administrativos e docentes do IFRN Campus Nova Cruz. A pesquisa possui caráter quantitativo, exploratório e descritivo. O universo da pesquisa é composto de iro servidores (66 docentes e 44 técnicos administrativos) com a participação de 46 docentes e 40 técnicos administrativos, que responderam um questionário baseado no instrumento EBACO, desenvolvido por Autor (ANO) totalizando, entre os dias 26 de junho a 07 de julho de 2017. Diante dos resultados obtidos, as Bases de comprometimento organizacional que apresentaram os maiores níveis de comprometimento foram Obrigação pelo Desempenho e Afetiva, e as que mostraram menor índices foram Escassez de Alternativas e Obrigação em Permanecer, para ambas as categorias. Em relação aos docentes, as Bases de comprometimento Obrigação pelo Desempenho apresentou um alto comprometimento com 93,5\% dos respondentes e a Base Afetiva 65\% dos docentes como nível acima da média. Em contrapartida, as Bases Obrigação em Permanecer e Escassez de Alternativas apresentaram os menores valores de comprometimento médio para os mesmos, com mais de $60 \%$ dos entrevistados apresentando baixo comprometimento. Com base nos resultados da pesquisa, encontrou-se que as Bases de comprometimento Obrigação pelo Desempenho com Ioo\% dos entrevistados se encontram com al to comprometimento e a Afetiva, apresentou $80 \%$ com nível acima da média, sendo os maiores valores para a categoria de servidores Administrativos, em compensação as Bases Obrigação em Permanecer e Escassez de Alternativas apresentaram os menores valores de comprometimento médio para os mesmos com 50\%.

Palavras-Chaves: Comprometimento Organizacional, Servidores, Docentes, IFRN, EBACO. 


\begin{abstract}
The organizational commitment has been studied by several methodologies in the last few decades, but its understanding is still at an early stage (MELO et al., 20I4; MEDEIROS, 2003), becoming a topic that arouses the interest of researchers to Organizational dimensions in different fields. Faced with the lack of studies that evaluated organizational commitment in educational institutions, the present study aimed to evaluate the organizational commitment of the administrative staff and Faculty of IFRN Campus Nova Cruz. The research universe is composed of iro servers, of which 66 are faculty members, and 44 administrative staff members. The sample was collected using the instrument EBACO, totalizing 46 teachers and 40 administrative staff members, from June 26 to July 7, 2017. The type of sampling used was non-probabilistic, for convenience. This study follows a quantitative paradigm, classified as exploratory and descriptive. In view of the results obtained, the Bases of organizational commitment that presented the highest levels of commitment were Performance and Affective Obligation, and the ones that showed lower rates were the Scarcity of Alternatives and Obligation to Stay, for both categories. Regarding the commitment of the teachers, such as Compulsory Bases for Compulsory Performance showed a high commitment with $93.5 \%$ of the respondents; also the Affective Base $65 \%$ of documents as enriched above the media. On the other hand, as Bases Obligation to Stay and Shortage of Alternatives presented the minors, according to more than $60 \%$ of respondents presenting low commitment. Based on the results of the survey, it was found that as Commitment Bases Performance Obligation with I00\% of respondents. If you are high committed and Afetiva, you have $80 \%$ with above average leader, the highest values being for the category of Administrative Officers, in compensation as Bases Obligation to Stay and Shortage of Alternatives presented the minors, with less than $50 \%$.
\end{abstract}

Keywords: Organizational commitment, Teachers, Servers, IFRN, EBACO. 


\section{INTRODUÇÃO}

O comprometimento organizacional tem sido estudado por diversas metodologias nas últimas décadas, porém, a sua compreensão ainda se encontra em fase inicial (MELO et al., 2014; MEDEIROS, 2003), tornando-se uma temática que desperta o interesse de pesquisadores a abordarem as dimensões do comprometimento organizacional em diversas áreas.

O conceito de comprometimento, difundido por Bastos (1994), consiste na busca de identificar e compreender fatores pessoais e profissionais que determinam o comportamento humano no trabalho (FONTON et al., 2002; BASTOS, 1994). Sendo os estudos sobre comprometimento uma forma de classificar o gral de envolvimento e afeição dos indivíduos com as organizações em que atuam.

Em reflexo a crescente procura de pesquisadores sobre o comprometimento dos indivíduos com suas distintas organizações, Medeiros (2003) identificou a necessidade de elaborar um instrumento para a mensuração dessa temática, desenvolvendo assim a Escala de Base do Comprometimento Organizacional (EBACO). O modelo desenvolvido é uma extensão do modelo de Meyer e Allen (1991), acrescentando o instrumento de O'Reilly and Chatman (1986), sendo incluídos 30 indicadores afetivos, normativos, instrumentais e afiliativos (MELO et al., 2014).

A primeira aplicação do EBACO foi realizada em 2003 por Medeiros. Desde então, vem sendo utilizado amplamente no Brasil por pesquisadores em diversos estudos, entre eles se destacam a Avaliação do comprometimento e da cultura organizacional (SANT'ANNA et al., 2014), Comprometimento organizacional como uma variável estratégica da gestão de pessoas (ENVALL et al., 2014), Confiança do empregado na organização e comprometimento organizacional (CUNHA et al., 2014), a geração Y e o seu comprometimento organizacional em empresas de conhecimento intensivo (PULINO et al., 2014) e Validação da escala de bases de comprometimento organizacional na gestão pública (MELO et al., 2014).

Apesar dos estudos já existentes sobre o comprometimento organizacional, ainda se percebe uma lacuna da literatura de mensurar comprometimento de docentes e servidores da área da educação. Desse modo, buscou-se avaliar a validade do modelo EBACO, proposto por Medeiros (2003), no Instituto Federal do Rio Grande do Norte (IFRN) Campus Nova Cruz, conhecendo assim os níveis de comprometimento organizacional da instituição, além da sua importância para a obtenção do título de Técnica em Administração e conclusão do referido curso.

O IFRN atua na área do ensino ofertando educação profissional e tecnológica de qualidade, comprometida com a formação dos indivíduos. Atualmente, a instituição possui cerca de 28 mil alunos em seus 21 campi distribuídos por todas as regiões do Estado (IFRN, 2017). O IFRN Campus Nova Cruz localiza-se na Avenida José Rodrigues de Aquino Filho, No 640, Alto de Santa Luzia. O campus atualmente dispõe de 116 servidores, que estão distribuídos da seguinte forma: 66 docentes, 06 estagiários, 44 técnicos administrativos, sendo este o universo da pesquisa.

Diante do exposto, o estudo tem por finalidade solucionar a seguinte questão de pesquisa: qual o nível de comprometimento organizacional dos docentes e servidores do IFRN/Campus Nova Cruz? Para atender à questão de pesquisa, o objetivo deste estudo é avaliar o comprometimento organizacional dos servidores e docentes do IFRN Campus Nova Cruz.

O Comprometimento Organizacional é uma das principais variáveis preditoras da performance de colaboradores em uma organização (Medeiros, 2003). Apesar de ser considerado um importante indicador, a literatura ainda é incipiente em mensurar comprometimento em organizações públicas. O EBACO foi validado por Melo et al., (2014) como um instrumento consistente e confiável, do ponto de vista metodológico, para estimar o nível de comprometimento organizacional em organizações públicas. Desse modo, tal instrumento foi adotado neste trabalho. Ademais, dada a relevância do Instituto Federal do Rio Grande do Norte na formação de cidadãos na Região Agreste e o impacto dos profissionais de educação como catalizadores de transformação social, se faz necessário avaliar o nível de comprometimento organizacional da referida instituição (FANTON, 2002).

O presente estudo contém além desta seção introdutória, uma revisão bibliográfica sobre o tema abordado, a metodologia utilizada, a análise dos resultados e em seguida, as considerações finais. 


\section{REVISÃO DA LITERATURA}

\section{Comprometimento organizacional}

O comprometimento organizacional nas últimas décadas tornou-se alvo de estudo de vários pesquisadores visando ajudar as organizações a encontrarem meios para tornar seus funcionários mais satisfeitos, engajados, envolvidos, e consequentemente, mais produtivos (REICHER; FONSECA, 2012).

Apesar de ter sido abordado consideravelmente no campo da gestão de pessoas, o Comprometimento Organizacional ainda não possui fronteiras epistemológicas e ontológicas bem delineadas (LEITE; ALBUQUERQUE, 2013). A corrente mais frequente na literatura é que o comprometimento está associado ao vínculo que o indivíduo estabelece com a organização e à medida que se envolve e compactua com os valores e as metas da instituição, como em Bastos (1994) e Bastos, Siqueira, Medeiros e Menezes (2008).

Segundo Reicher e Fonseca (2012), as definições de comprometimento implicam a noção de algo que amarra, une o indivíduo a alguma coisa, expressando a ideia de adesão, de forte envolvimento do indivíduo com aspectos diversos do contexto de trabalho, resumindo-se em um conjunto de sentimentos e ações em relação à sua instituição, também sendo citado por Paiva e Morais (2012), como uma das bases para a interatividade, pois reflete o envolvimento do sujeito com seu trabalho, pessoas e, num nível macro, com a própria organização.

Este sentimento de pertencer, de fazer parte da organização, é estudado pelo comprometimento, visando não só um melhor desempenho da instituição, mas tornar os funcionários mais produtivos e comprometidos com a profissão e o papel que devolvem dentro da organização. Como afirmam Sant'anna et al. (2014) e Luna e Baptista (2001), os estudos sobre comprometimento organizacional visam contribuir e auxiliar as organizações a compreenderem o envolvimento do ser humano no trabalho e a sua satisfação com a atividade desenvolvida. Ainda nesta perspectiva Rego (2002) e Traldi e Demo (2012) relatam que as pessoas mais comprometidas têm mais chances de permanecerem na organização e de se empenharem na execução do seu trabalho e dos objetivos organizacionais.

\section{Dimensões do comprometimento}

Os estudos sobre comprometimento organizacional apresentam diversas dimensões organizais. Dentre os modelos encontrados na literatura, o modelo EBACO adota sete dessas bases, que são classificadas da seguinte forma: Afetivo (Internalização de Valores e Objetivos), Instrumental (Poucas Alternativas); (Recompensas e Oportunidades); (Linha Consistente de Atividade); Normativo (Obrigação em Permanecer); (Obrigação pelo Desempenho); e Afiliativo (Sentimento de Fazer Parte). As sete dimensões apresentadas serão analisadas a seguir, revelando algumas características do comprometimento dos indivíduos.

A dimensão afetiva (Internalização de Valores e Objetivos) representa a natureza do processo de identificação do indivíduo com os objetivos e valores da organização e o desejo de permanecer na organização, de modo a contribuir para o alcance desses objetivos (MELO et al., 2014; BASTOS, 1993; TAMAYO, 2008). Esta base ancora-se nos sentimentos e na afeição que o indivíduo expressa pela instituição; segundo Reicher e Fonseca (2012) Meyer e Allen (1997) o comprometimento afetivo acontece quando os funcionários têm apego, afeto, estabelecendo vínculos emocionais com a instituição.

Para Traldi e Demo (2012) e Mowday, Porter e Steers (1982), o comprometimento afetivo pode ser definido pelas suas principais características: crença e aceitação dos objetivos e valores organizacionais; disposição para defender a instituição e o desejo de manter o vínculo com ela. Supondo-se uma entrega por parte do indivíduo para contribuir com o sucesso e bem-estar da organização. 
Ao se tratar da base Instrumental, temos três enfoques enfoques principais, denominados por Sant'anna et al. (2014) e Bastos et al. (2008), como: a) Poucas alternativas: o indivíduo possui poucas alternativas de trabalho se deixar a organização; b) Recompensas e oportunidades: acredita-se que o esforço extra realizado em benefício da organização deve ser recompensado e de que a organização deve lhe dar mais oportunidades; e c) Linha Consistente de atividade: crença de que deve manter certas atitudes e cumprir as regras da organização com objetivo de se manter nela.

O comprometimento, a partir do enfoque instrumental, é visto em função das recompensas e custos associados ao trabalho, o indivíduo opta por permanecer na empresa enquanto perceber os benefícios recebidos em troca (BECKER, 1960; CANÇADO et al., 2007). Este enfoque aborda as consequências associadas à saída da instituição, levando em consideração também os custos para fazer parte da organização, o tempo já dedicado a ela e os benefícios e retornos conquistados.

Para Cunha et al. (2014) e Meyer e Allen (1997), a base instrumental se refere à consciência de custos que o indivíduo tem ao deixar de trabalhar na sua empresa, permanecendo assim, na organização por achar conveniente, diante da escarces de oportunidades no mercado de trabalho ou pelas recompensas obtidas.

O enfoque normativo segundo Paiva e Morais (2012), representa o compromisso e o dever que o indivíduo tem com a organização, de seguir as regras e normas em função de sua fidelidade, e ainda como se fosse obrigatório ou um dever ético com a instituição. Esta dimensão do comprometimento organizacional se classifica em duas formas: obrigação em permanecer e obrigação pelo desempenho.

A obrigação em permanecer consiste na crença de que o indivíduo tem uma obrigação em permanecer na instituição, sentindo-se culpado em deixá-la, tendo uma obrigação moral com as pessoas; já a obrigação pelo desempenho é a crença de que deve se esforçar em benefício da organização e que deve desempenhar as tarefas e atingir os objetivos organizacionais (SANT'ANNA et al., 2014; BASTOS et al., 2008).

Neste sentido, a dimensão normativa remete a obrigatoriedade, as pessoas permanecem nas instituições por se sentirem obrigadas, pelo sentimento de estar em dívida com ela ou pelo fato de sentir uma obrigação moral e ética com os indivíduos da organização.

Por fim, temos a base afiliativa, que consiste no sentimento de fazer parte da organização. Esta dimensão pouco abordada na literatura diz respeito à percepção do indivíduo de ser reconhecido como um membro da organização por seus colegas. Sendo esta tese reforçada por estudiosos como Melo et al. (2014), Medeiros e Enders (1999) e Medeiros (2005).

As bases citadas anteriormente abordam como o comprometimento organizacional pode ser classificado diante das relações que o indivíduo mantém com a organização, sendo esses os constructos teóricos que fundamentam o instrumento desta pesquisa, o EBACO, que será descrito na seção seguinte.

A próxima seção também irá apresentar os elementos metodológicos da pesquisa. Serão descritos a população e amostra, instrumento de coleta, forma de aplicação dos questionários e enquadramento do estudo. 


\section{METODOLOGIA DA PESQUISA}

A presente pesquisa teve como objeto de estudo o IFRN Campus Nova Cruz. O universo da pesquisa é formado pelos 110 servidores do campus (66 docentes e 44 técnicos administrativos), dos quais 46 docentes e 40 técnicos administrativos responderam os questionários - os demais 24 servidores faltantes não foram encontrados no Campus ou estavam de férias durante o período de realização da pesquisa.

A coleta dos dados foi realizada entre os dias 26 de junho a 07 de julho de 2017, através da utilização de um instrumento de Escala de Bases do Comprometimento Organizacional, formado por 36 questões, das quais 28 perguntas fechadas, oscilando de 01 a 06 , de menor à maior concordância, e mais oito questões objetivas para avaliar variáveis como: idade, sexo, estado civil, grau de escolaridade, o vínculo empregatício e a área de atuação na organização, e o período que o indivíduo atua em sua função atual e na instituição. O modelo EBACO possui sete fatores de comprometimento organizacional: afetivo, obrigação em permanecer, obrigação pelo desempenho, afiliativo, falta de recompensas e oportunidades, linha consistente de atividades e escassez de alternativas. Cada base de comprometimento compõe quatro itens do questionário.

A interpretação dos dados foi feita com base no artigo de Medeiros (2003), a abordagem adotada na pesquisa foi quantitativa, através da análise das informações numéricas resultantes da investigação e modelos estatísticos para explicar os dados, como conjuntos de quadros e tabelas (SABINO, 1966; BAUER E GASKELL, 2003; LAKATOS E MARCONI, 2010).

No que diz respeito a sua classificação, esta pesquisa classifica-se como exploratória descritiva. Segundo Gil (2009), as pesquisas exploratórias têm como finalidade desenvolver, esclarecer e modificar conceitos e ideias, e são desenvolvidas com o objetivo de proporcionar visão geral e aproximada acerca de determinado fato. As pesquisas descritivas têm como objetivo a descrição das características de determinado grupo como sua distribuição por idade, sexo, nível de escolaridade (GIL, 2009).

Os dados coletados para a realização desta pesquisa foram colhidos de maneira sigilosa, garantindo confidencialidade aos respondentes, tais informações serão utilizadas exclusivamente para fins científicos.

$\mathrm{Na}$ seção seguinte será feita a análise e discursão dos resultados, bem como a comparação do nível de comprometimento entre os docentes e servidores.

\section{RESULTADOS E DISCUSSÕES}

\section{Análise do perfil dos servidores administrativos}

Esta seção irá discorrer sobre o perfil dos 40 servidores técnicos administrativos participantes desta pesquisa. Serão apresentadas tabelas e gráficos sobre as principais variáveis coletadas no estudo, relativa às características pessoais e o nível de comprometimento dos entrevistados.

O Gráfico 1 apresenta dados sobre o sexo dos servidores técnico-administrativos do IFRN. Dos 40 servidores que responderam ao questionário $47,5 \%$ foram respondentes do sexo masculino, 47,5\% do sexo feminino e $5 \%$ dos entrevistados desejaram não informar seu sexo.

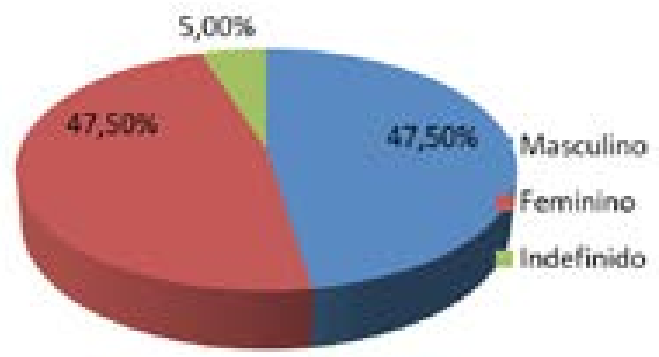

Gráfico I - Sexo dos técnicos administrativos do IFRN Campus Nova Cruz, 20I7.

Fonte: Dados da pesquisa (20I7). 
O segundo Gráfico desta seção mostra a faixa etária dos servidores, na qual 12,5\% dos respondentes têm até 25 anos, $40 \%$ se encontram entre 26 e 30 anos, $30 \%$ têm de 31 a 35 anos e 17,5\% mais de 35 anos.

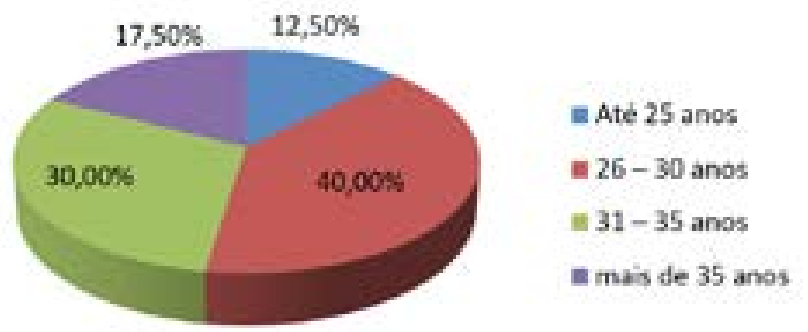

Gráfico 2 - Faixa etária dos técnicos administrativos do IFRN Campus Nova Cruz, 2017 .

Fonte: Dados da pesquisa (2017).

O estado civil dos servidores é representado pelo Gráfico 3, no qual se observa que $37,5 \%$ dos respondentes são solteiros, $60 \%$ casados e 2,5\% são divorciados. Esse índice referente ao percentual de casados pode ser explicado pelo fato de mais de $80 \%$ dos técnicos terem mais de 26 anos.

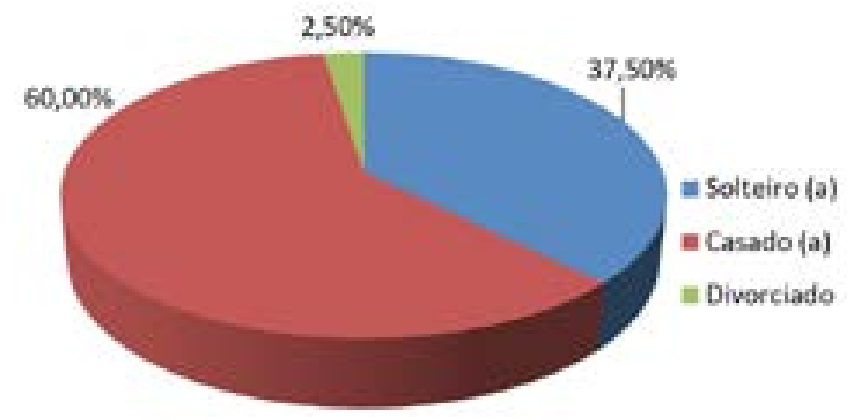

Gráfico 3 - Estado civil dos técnicos administrativos do IFRN Campus Nova Cruz, 2017.

Fonte: Dados da pesquisa (2017).

No Gráfico 4, está presente o grau de escolaridade participantes da pesquisa. Dos servidores que responderam o questionário $2,5 \%$ tem $2^{\circ}$ grau completo, $10 \%$ superior incompleto, $30 \%$ superior completo, $10 \%$ pós-graduação incompleta e $47,5 \%$ pós-graduação completa, refletindo que as atividades do IFRN demandam um maior nível de qualificação.

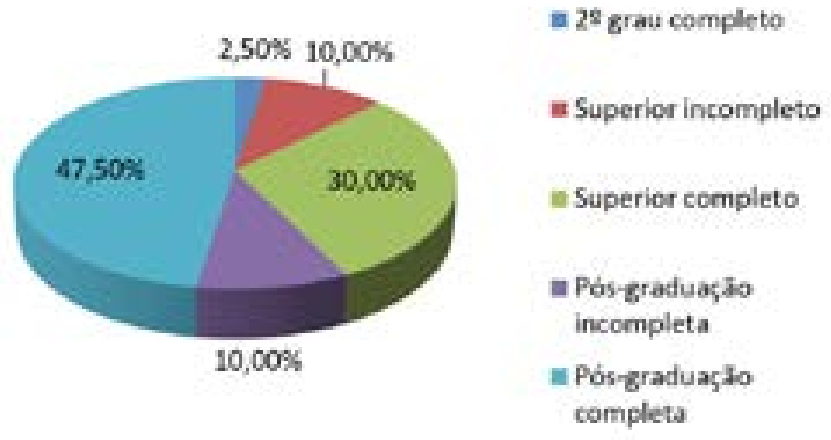

Gráfico 4 - Grau de escolaridade dos técnicos administrativos do IFRN Campus Nova Cruz, 2017 .

Fonte: Dados da pesquisa (2017).

O Gráfico 5 detalha o tempo de trabalho dos técnicos na instituição. Sendo que 7,5\% estão a menos de um ano na organização, 87,5\% de 1 a 5 anos, $5 \%$ de 6 a 10 anos e a mais de 10 anos $0 \%$ devido ao fato de ser um instituto relativamente recente. 


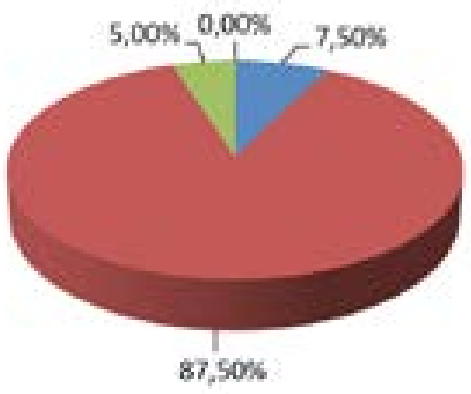

Menos de 1 ang

$=1-5$ anos

$=6-10$ anes

EMais de 10 anos
Gráfico 5 - Tempo de trabalho dos técnicos administrativos do IFRN Campus Nova Cruz, 2017 .

Fonte: Dados da pesquisa (2017).

O tempo de cargo/ função dos servidores na organização está sendo representado pelo Gráfico 6. Os resultados demostram que 20\% estão a menos de 1 anos na instituição, 77,5\% de 1 a 5 anos e 2,5\% de 6 a 10 anos, revelando que mais de $70 \%$ dos servidores já estão a um período considerável no instituto.
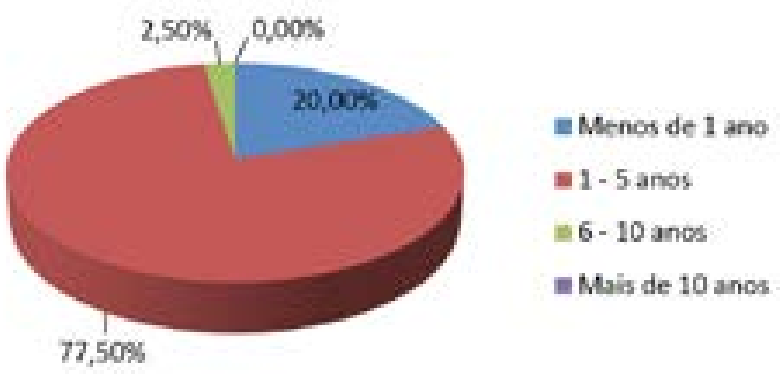

Gráfico 6 - Tempo de cargo/ função na organização dos técnicos administrativos do IFRN Campus Nova Cruz, 2017.

Fonte: Dados da pesquisa (2017).

O último Gráfico desta seção traz o vínculo empregatício dos servidores com a instituição. Observase que $100 \%$ dos técnicos administrativos são servidores efetivos devido à natureza da instituição e da forma de contratação via concurso público. Ressalta-se que até a presente data, não existe a figura do servidor técnico administrativo substituto ou contratado temporariamente, diferentemente do que ocorre com a categoria docente.

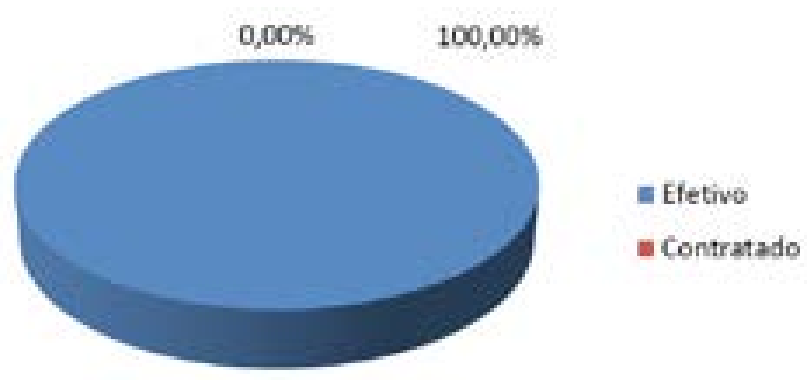

Gráfico 7 - Vínculo empregatício dos técnicos administrativos do IFRN Campus Nova Cruz, 2017 .

Fonte: Dados da pesquisa (2017).

A Tabela a seguir discorrerá sobre os dados referentes aos níveis de comprometimento dos servidores e suas respectivas bases. A base Obrigação pelo Desempenho foi a que apresentou o nível mais alto de comprometimento com 100\% dos respondentes, a qual remete que é necessário fazer um esforço em benefício da organização, cumprir as obrigações e atingir os objetivos organizacionais. Assim como no estudo realizado por Pulino (2014) a base de comprometimento organizacional em apresentou alto comprometimento foi a Obrigação pelo desempenho. 
A base Afetiva apresentou $80 \%$ dos técnicos com comprometimento acima da média, e $20 \%$ com alto comprometimento, a dimensão em questão é caracterizada pela internalização de valores e a identificação do indivíduo com os objetivos da organização.

O sentimento de culpa se deixar a instituição é uma característica da dimensão Obrigação em Permanecer, a qual teve como baixo comprometimento 50\%, comprometimento abaixo da média 35\% e comprometimento acima da média 15\%, sendo que este segundo Medeiros (2003) deveria ser acima da média.

A dimensão Escassez de Alternativas está com $50 \%$ do total dos servidores baixo comprometimento, $30 \%$ abaixo da média, $15 \%$ acima da média e 5\% com alto comprometimento, esses resultados inferem que $80 \%$ do total tem perspectiva de que há poucas opções de trabalho se deixar a organização.

A base Afiliativa apresentou baixo comprometimento com 45\% dos respondentes, 37\% comprometimento abaixo da média, $15 \%$ acima da média e $2 \%$ alto comprometimento, demostrando que os técnicos têm um fraco sentimento de pertencer à instituição.

A dimensão Falta de Recompensas e Oportunidades expôs um baixo comprometimento com $22 \%$, abaixo da média $65 \%$ e acima da média com $12 \%$, mostrando que os servidores não se sentem devidamente recompensados e há poucas oportunidades para crescer profissionalmente na instituição.

E por fim, a Linha Consistente de Atividades demonstrou baixo comprometimento representando $15 \%$ dos técnicos, comprometimento abaixo da média $47 \%$, acima da média $35 \%$ e alto comprometimento $2 \%$, na qual esta base enfatiza que se deve cumprir as regras para permanecer na instituição, visando os gastos que teria se a deixar.

\begin{tabular}{|c|c|c|c|c|c|c|}
\hline \multicolumn{2}{|l|}{ Bases } & $\begin{array}{l}\text { Baixo } \\
\text { comprometimento }\end{array}$ & $\begin{array}{l}\text { Comprometimento } \\
\text { abaiko da média }\end{array}$ & $\begin{array}{l}\text { Comprometimento } \\
\text { acima da média }\end{array}$ & $\begin{array}{l}\text { Alto } \\
\text { comprometimento }\end{array}$ & Total \\
\hline \multirow{2}{*}{$\begin{array}{l}\text { Base: } \\
\text { Afetivo }\end{array}$} & fi & & & 32 & 8 & 40 \\
\hline & $\underline{n i} \%$ & & & $80 \%$ & $20 \%$ & $100 \%$ \\
\hline \multirow{4}{*}{$\begin{array}{c}\text { Base: } \\
\text { Obrigacho em } \\
\text { Permanecer } \\
\text { Base: } \\
\text { Obrigac2o pelo } \\
\text { Desempenho }\end{array}$} & fi & 20 & 14 & 6 & & 40 \\
\hline & $\underline{\text { nit\% }}$ & $50 \%$ & $35 \%$ & $15 \%$ & & $100 \%$ \\
\hline & fi & & & & 40 & 40 \\
\hline & $\underline{n} 1 \%$ & & & & $100 \%$ & $100 \%$ \\
\hline \multirow{2}{*}{ Base: Aflliatha } & fi & 18 & 15 & 6 & 1 & 40 \\
\hline & nim & $45 \%$ & $37 \%$ & $15 \%$ & $2 \%$ & $100 \%$ \\
\hline \multirow{2}{*}{$\begin{array}{l}\text { Base: Falta de } \\
\text { Recompensas e } \\
\text { Oportunidades }\end{array}$} & fi & 9 & 26 & 5 & & 40 \\
\hline & nis\% & $22 \%$ & $65 \%$ & $12 \%$ & & $100 \%$ \\
\hline \multirow{2}{*}{$\begin{array}{l}\text { Base: Unho } \\
\text { Consistente de } \\
\text { Atividade }\end{array}$} & fi & 6 & 19 & 14 & 1 & 40 \\
\hline & $\underline{n i} \%$ & $15 \%$ & $47 \%$ & $35 \%$ & $2 \%$ & $100 \%$ \\
\hline \multirow{2}{*}{$\begin{array}{l}\text { Base: Escassez de } \\
\text { Alternathus }\end{array}$} & fi & 20 & 12 & 6 & 2 & 40 \\
\hline & $\underline{n} 1 \%$ & $50 \%$ & $30 \%$ & $15 \%$ & $5 \%$ & $100 \%$ \\
\hline
\end{tabular}

Tabela I - Resumo de distribuição de Frequências de Comprometimento Organizacional dos Técnicos Administrativos no IFRN Campus Nova Cruz, 20I7.

Fonte: Dados da pesquisa (2017).

As Tabelas seguintes discorrerão sobre as estatísticas descritivas de cada base, bem como algumas variáveis. A Tabela 2 apresenta as estatísticas descritivas referentes à Base Afetiva dos servidores administrativos do IFRN Campus Nova Cruz. 
Base Afetiva

\begin{tabular}{|cc|}
\hline Média & 15,28 \\
\hline Erro padrão & 0,24 \\
\hline Modo & 15,4 \\
\hline Desvio padrão & 1,56 \\
\hline Variância & 2,46 \\
\hline Intervalo & 6,16 \\
\hline Mínimo & 12,32 \\
\hline Máximo & 18,48 \\
\hline Contagem & 40 \\
\hline
\end{tabular}

Tabela 2 - Estatísticas descritivas da Base Afetiva dos servidores Administrativos.

Fonte: Dados da pesquisa (2017).

$\mathrm{Na}$ Base Afetiva a média de comprometimento foi de 15,28. Este resultado é considerado acima da média na escala EBACO, indicando um grau de relacionamento afetivo entre os servidores administrativos e a instituição. Com relação ao erro padrão, seu valor foi de 0,24 . Os desvios-padrão e variância apresentaram valores considerados baixos, sendo o desvio padrão de 1,56 e variância da amostra 2,46, indicando homogeneidade nas respostas dos servidores. Por fim, o intervalo foi de 6,16, sendo o mínimo de 12, 32 e o máximo de 18,48.

A Tabela 3 apresenta os dados relativos à Base Obrigação em Permanecer dos servidores do IFRN Campus Nova Cruz no ano de 2017.

\begin{tabular}{|cc|}
\hline Base Obrigação em Permanecer \\
\hline Média & 10,83 \\
\hline Erro padrão & 0,65 \\
\hline Modo & 12,07 \\
\hline Desvio padrão & 4,14 \\
\hline Variância & 17,16 \\
\hline Intervalo & 16,2 \\
\hline Mínimo & 3,24 \\
\hline Máximo & 19,44 \\
\hline Contagem & 40 \\
\hline
\end{tabular}

Tabela 3 - Estatística descritiva da Base Obrigação em Permanecer dos Servidores. Tabela 3 - Estatística descritiva da Base Obrigação em Permanecer dos Servidores.

Fonte: Dados da pesquisa (2017).

A Base Obrigação em Permanecer apresentou comprometimento abaixo da média, com a média de 10,83. O modo de 12,07, os desvios-padrão e a variância obtiveram níveis muito altos, demostrando respostas bastantes heterogenias. O intervalo foi de 16,2, com o mínimo de 3,24 e o máximo de 19,44.

A Tabela 4 contem os dados relativos à Base Obrigação pelo Desempenho dos servidores do IFRN Campus Nova Cruz no ano de 2017. 


\begin{tabular}{|cc|}
\hline Base Obrigação pelo Desempenho \\
\hline Média & 16,95 \\
\hline Erro padrão & 0,18 \\
\hline Modo & 17,82 \\
\hline Desvio padrão & 1,16 \\
\hline Variância & 1,35 \\
\hline Intervalo & 3,62 \\
\hline Mínimo & 14,2 \\
\hline Máximo & 17,82 \\
\hline Contagem & 40 \\
\hline
\end{tabular}

Tabela 4 - Estatística descritiva da Base Obrigação pelo Desempenho dos Servidores.

Fonte: Dados da pesquisa (2017).

A Dimensão Obrigação pelo Desempenho que teve o mais alto índice de comprometimento com média de 16,95. O erro padrão de 0,18, o desvio-padrão 1,16 e a variância 1,35 sendo considerados relativamente baixos mostrando homogeneidade nas respostas, o intervalo com 3,62 também foi baixo, com o mínimo de 14,2 e o máximo de 17,82.

A Tabela 5 contém os dados referentes à Base Afiliativa dos servidores do IFRN Campus Nova Cruz no ano de 2017.

\begin{tabular}{|cc|}
\hline \multicolumn{2}{|c}{ Base Afiliativa } \\
\hline Média & 14,44 \\
\hline Erro padrão & 0,36 \\
\hline Modo & 17,2 \\
\hline Desvio padrão & 2,30 \\
\hline Variância & 5,32 \\
\hline Intervalo & 8,22 \\
\hline Mínimo & 9,66 \\
\hline Máximo & 17,88 \\
\hline Contagem & 40 \\
\hline
\end{tabular}

Tabela 5 - Estatística descritiva da Base Afiliativa dos servidores Administradores.

Fonte: Dados da pesquisa (2017).

A Base Afiliativa teve média de 14,44, representando baixo comprometimento. Sendo o desvio padrão de 2,30 , e a variância de 5,32 , considerados relativamente altos, o erro padrão de 0,36 , o modo 17,2 e o intervalo 8,22 com o mínimo de 9,66 e o máximo de 17,88.

A Tabela 6 apresenta os dados relativos à Base Falta de Recompensas e Oportunidades dos servidores do IFRN Campus Nova Cruz no ano de 2017. 


\begin{tabular}{|cc|}
\hline $\begin{array}{c}\text { Base Falta de Recompensas e } \\
\text { Oportunidades }\end{array}$ \\
\hline Média & 6,13 \\
\hline Erro padrão & 0,32 \\
\hline Modo & 10,16 \\
\hline Desvio padrão & 2,07 \\
\hline Variância & 4,28 \\
\hline Intervalo & 8,49 \\
\hline Mínimo & 2,99 \\
\hline Máximo & 11,48 \\
\hline Contagem & 40 \\
\hline
\end{tabular}

Tabela 6 - Estatística descritiva da Base Falta de Recompensas e Oportunidades dos servidores.

Fonte: Dados da pesquisa (2017).

Apresentando comprometimento abaixo da média a Base Falta de Recompensas e Oportunidades obteve média de 6,13, com erro padrão de 0,32 e o modo 10,16. A variância 4,28 e o desvio padrão 2,07, demostrando que as respostas não são homogenias. O intervalo de 8,49, sendo o mínimo de 2,99 e o máximo de 11,48.

A Tabela 7 mostra o índice referente à Base Linha Consistente de Atividades dos servidores do IFRN Campus Nova Cruz no ano de 2017.

\section{Base Linha de Consistente de} Atividades

\begin{tabular}{|cc|}
\hline Média & 11,39 \\
\hline Erro padrão & 0,34 \\
\hline Modo & 14,36 \\
\hline Desvio padrão & 2,18 \\
\hline Variância & 4,75 \\
\hline Intervalo & 9,27 \\
\hline Mínimo & 6,51 \\
\hline Máximo & 15,78 \\
\hline Contagem & 40 \\
\hline
\end{tabular}

Tabela 7- Estatística descritiva da Base Linha Consistente de atividades dos servidores.

Fonte: Dados da pesquisa (2017).

Os índices da Base Linha Consistente de Atividades foram os seguintes: média de 11,39 representando comprometimento acima da média, erro padrão de 0,34 e o modo 14,36. O desvio padrão, a variância e o intervalo considerados altos, sendo o mínimo do intervalo 6,51 e o máximo 15,78.

A Tabela 8 faz inferência aos índices referente à Base Escassez de alternativas dos servidores do IFRN Campus Nova Cruz no ano de 2017. 
Base Escassez de Alternativas

\begin{tabular}{|cc|}
\hline Média & 11,17 \\
\hline Erro padrão & 0,62 \\
\hline Modo & 7,73 \\
\hline Desvio padrão & 3,97 \\
\hline Variância & 15,81 \\
\hline Intervalo & 14,9 \\
\hline Mínimo & 2,98 \\
\hline Máximo & 17,88 \\
\hline Contagem & 40 \\
\hline
\end{tabular}

Tabela 8- Estatística descritiva da Base Escassez de Alternativas dos servidores.

Fonte: Dados da pesquisa (2017).

A última Base a ser analisada nesta seção é a Escassez de Alternativas, tendo sua média de 11,17 é classificada como de baixo comprometimento, com erro padrão de 0,62, o desvio padrão é de 3,97 e a variância com índice altíssimo de 15,81 pelo fato das respostas não serem homogêneas. O mínimo do intervalo foi de 2,98 e o máximo de 17,88, sendo o intervalo de 14,9.

De modo geral, percebe-se que o nível de comprometimento organizacional dos servidores administrativos foi elevado. Destacam-se as bases Obrigação pelo Desempenho, com 100\% dos entrevistados se encontram com alto comprometimento e a Afetiva, apresentou $80 \%$ com nível acima da média, sendo os maiores valores para a categoria de servidores Administrativos, em compensação as Bases Obrigação em Permanecer e Escassez de Alternativas apresentaram os menores valores de comprometimento médio para os mesmos com 50\%. Resultados semelhantes foram encontrados por Pulino, Kubo e Oliva (2014) e Cunha, Silva, Moura, Horbe, Bule e Vargas (2014).

A próxima seção fará uma análise no perfil dos docentes e no nível de comprometimento organizacional encontrado e suas respectivas bases, assim como foi feito com a categoria dos servidores.

\section{Análise do perfil dos docentes}

No desenvolver desta seção serão apresentados o perfil e os resultados dos questionários aplicados aos 46 docentes que fizeram parte da amostra da presente pesquisa. Serão apresentados gráficos e tabelas referentes a características pessoais dos entrevitados e outras variáveis abordadas no estudo.

O Gráfico 8 contém dados referente ao sexo dos docentes. O gênero masculino é composto por $60,9 \%$ dos docentes, feminino $34,8 \%$ e $4,3 \%$ desejaram não se identificar, diferentemente do perfil dos servidores, o gênero masculino é marjoritário na presente categoria. 


\section{ISSN - 2447-178X}
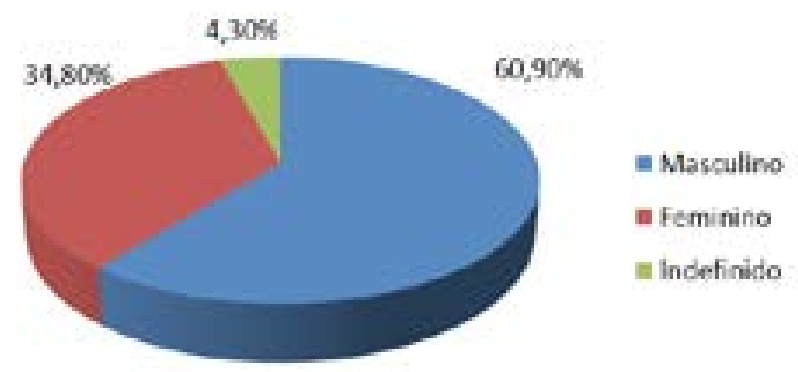

Gráfico 8 - Sexo dos docentes do IFRN Campus Nova Cruz, 2017 .

Fonte: Dados da pesquisa (2017).

Os dados alusivos a faixa etária dos docentes está presente no Gráfico 9, sendo 19,6\% de 26 a 30 anos, $50 \%$ de 31 a 35 anos e 30,43\% maiores de 35 a nos de idade, tais resultados pedem ser compreendidos a partir do momento que os docentes necessitam de uma especialização maior para excer suas funções o que acarreta em uma faixa etária maior.
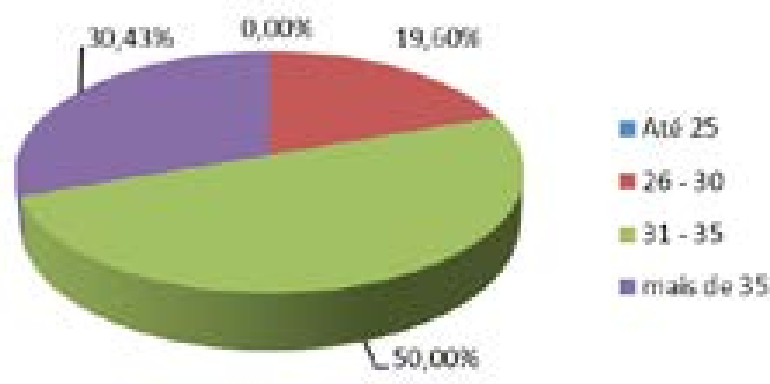

Gráfico 9 - Faixa etária dos docentes do IFRN Campus Nova Cruz, 2017.

Fonte: Dados da pesquisa (2017).

O estado civil é representado pelo Gráfico 10, no qual 34,8\% dos respondentes são solteiros, 56,5\% casados e $8,7 \%$ são divorciados, esses dados podem ser explicados pela faixa etária dos participantes, que é composta por mais de $70 \%$ dos docentes maiores de 31 anos.
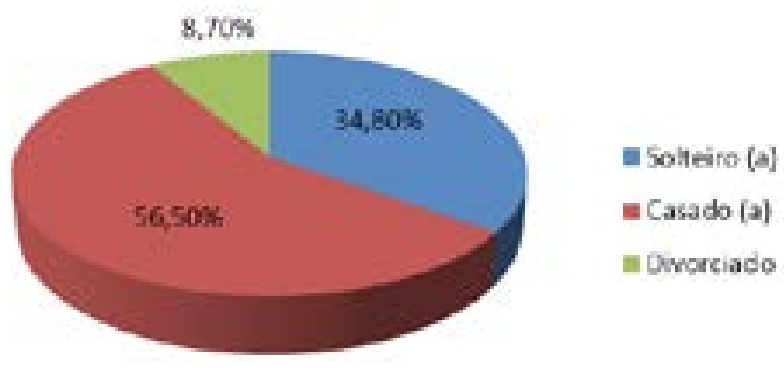

Gráfico io- Estado civil dos docentes do IFRN Campus Nova Cruz, 2017.

Fonte: Dados da pesquisa (20I7).

No Gráfico 11, é possível analisar o grau de escolaridade dos docentes, que se distribuíram da seguinte forma: 4,3\% com o ensino superior completo, 2,2\% com pós-graduação incompleta e 93,5\% com a pós-graduação completa.

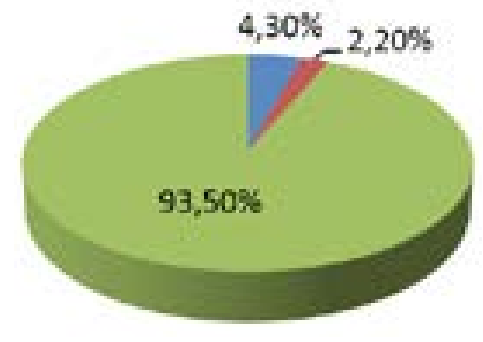

Vol.1 (2017)

= Superior completo

= Pós-graduaç̧̃o incompleta

= Pós-graduação completa
Gráfico II-Grau de escolaridade dos docentes do IFRN Campus Nova Cruz, 2017.

Fonte: Dados da pesquisa (2017). 
No Gráfico 12, estão presentes os dados sobre o vínculo empregatício dos docentes com o IFRN, destacando-se que $80,4 \%$ são efetivos e 19,6\% contratados, tendo em vista que é possível a contratação de docentes substitutos.
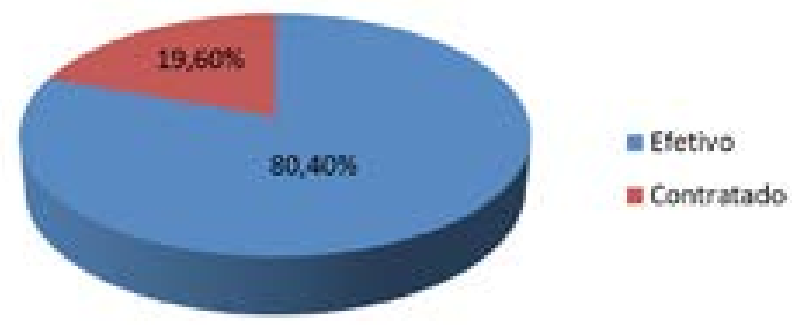

Gráfico i2- Vínculo empregatício dos docentes do IFRN Campus Nova Cruz, 2017.

Fonte: Dados da pesquisa (2017).

O tempo de trabalho dos docentes está exposto no Gráfico 13. Os resultados referentes a esse perfil se distribuiram em, 15,2\% trabalham a menos de 1 ano, 58,7\% entre 1 e 5 anos, 23,9\% de 6 a 10 anos e 2,2\% a mais de 10 anos, sendo visível que mais da metade dos entrevistados já trabalham entre 1 e 5 anos.

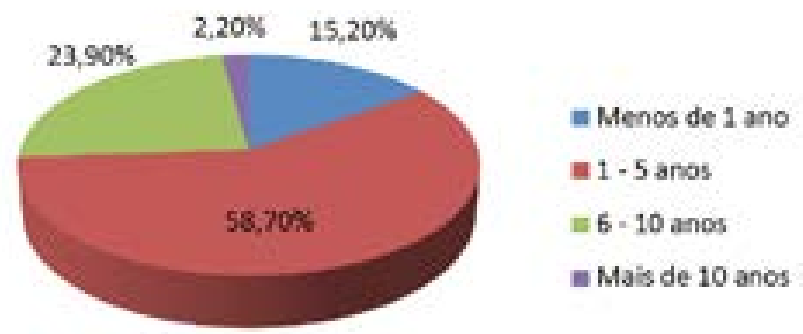

Gráfico iz- Tempo de trabalho dos docentes do IFRN Campus Nova Cruz, 2017.

Fonte: Dados da pesquisa (2017).

Em relação ao tempo que o docente ocupa na função/cargo este doados são apresentado no Gráfico 14 a seguir, sendo que 13\% deles estão a menos de 1 ano no cargo, 43,5\% de 1 a 5 anos, 28,3\% de 6 a 10 anos, $2,2 \%$ de 11 a 15 anos, $8,7 \%$ entre 16 e 20 anos e 4,3\% estão a mais de 20 anos na mesma função.
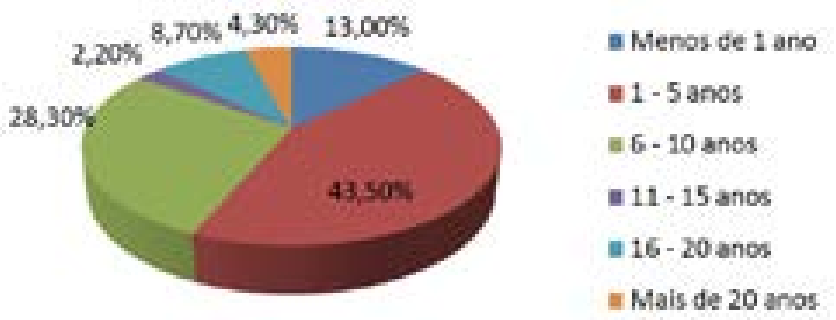

Gráfico I4- Tempo de cargo/função na organização dos docentes do IFRN Campus Nova Cruz, 2017.

Fonte: Dados da pesquisa (2017).

A Tabela a seguir descreve o nível de comprometimento organizacional dos docentes segundo os dados coletados na pesquisa. A Base Obrigação pelo Desempenho foi a que obteve o nível mais alto de comprometimento com $93 \%$ e acima da média com 7\%, demonstrando que essa categoria assim como a dos servidores está dentre os padrões desejados de comprometimento.

A dimensão Afetiva em $65 \%$ dos resultados apresentou comprometimento acima da média, 20\% alto comprometimento e 15\% comprometimento abaixo da média, mostrando que os docentes se identificam com a filosofia da instituição. 
Quanto à Base Obrigação em Permanecer os índices foram baixos, sendo 61\% com baixo comprometimento, $20 \%$ abaixo da média e $20 \%$ acima da média, inferindo que estes não sentem nenhuma obrigação moral para com a instituição ou seus colegas de trabalho.

A Base Afiliativa se distribui da seguinte maneira: 57\% com baixo comprometimento, $28 \%$ abaixo da média, $9 \%$ acima da média e 7\% com alto comprometimento, apresentando resultado semelhante à categoria dos servidores.

$\mathrm{Na}$ dimensão Escassez de Alternativas se obteve os resultados de 67\% baixo comprometimento, $24 \%$ comprometimento abaixo da média e $9 \%$ acima de média, na qual a maioria compreende que existe escassez de alternativas de trabalho caso deixe o instituto.

No que se refere à Falta de Recompensas e Oportunidades o estudo revela que 37\% dos docentes estão com baixo comprometimento e $63 \%$ abaixo da média, apresentando níveis ainda mais baixos que os dos técnicos administrativos.

A Linha Consistente de Atividades se apresentou, sendo $22 \%$ dos docentes com baixo comprometimento, $37 \%$ abaixo da média, 37\% acima da média e 4\% com comprometimento alto, condizendo com a realidade dos percebida pelos servidores.

\begin{tabular}{|c|c|c|c|c|c|c|}
\hline Bases & & $\begin{array}{c}\text { Baixo } \\
\text { Comprometimen } \\
\text { To } \\
\end{array}$ & $\begin{array}{c}\text { Comprometime } \\
\text { nto abaixo da } \\
\text { média }\end{array}$ & $\begin{array}{l}\text { Comprometime } \\
\text { nto acima da } \\
\text { média }\end{array}$ & $\begin{array}{c}\text { Alto } \\
\text { comprometimen } \\
\text { to } \\
\end{array}$ & Total \\
\hline \multirow{2}{*}{ Base: Afetiva } & fi & & 7 & 30 & 9 & 46 \\
\hline & nil\% & & $15 \%$ & $65 \%$ & $20 \%$ & $100 \%$ \\
\hline \multirow{4}{*}{$\begin{array}{c}\text { Base: } \\
\text { Obrigação em } \\
\text { Permanecer } \\
\text { Base: } \\
\text { Obrigaçăo pelo } \\
\text { Desempenho }\end{array}$} & fi & 28 & 9 & 9 & & 46 \\
\hline & Dil\% & $61 \%$ & $20 \%$ & $20 \%$ & & $100 \%$ \\
\hline & fi & & & 3 & 43 & 46 \\
\hline & ais & & & $7 \%$ & $93 \%$ & $100 \%$ \\
\hline \multirow{2}{*}{ Base: Afiliativa } & Ii & 26 & 13 & 4 & 3 & 46 \\
\hline & nir & $57 \%$ & $28 \%$ & $9 \%$ & $7 \%$ & $100 \%$ \\
\hline \multirow{4}{*}{$\begin{array}{c}\text { Base: Falta de } \\
\text { Recompensas e } \\
\text { Oportunidades } \\
\text { Base: Linha } \\
\text { Consistente de } \\
\text { Atividade }\end{array}$} & fi & 17 & 29 & & & 46 \\
\hline & nits & $37 \%$ & $63 \%$ & & & $100 \%$ \\
\hline & fi & 10 & 17 & 17 & 2 & 46 \\
\hline & aid\% & $22 \%$ & $37 \%$ & $37 \%$ & $4 \%$ & $100 \%$ \\
\hline \multirow{2}{*}{$\begin{array}{l}\text { Base: Escassez } \\
\text { de Alternativas }\end{array}$} & fi & 31 & 11 & 4 & & 46 \\
\hline & ai\% & $67 \%$ & $24 \%$ & $9 \%$ & & $100 \%$ \\
\hline
\end{tabular}

Tabela 9 - Resumo de distribuição de Frequências de Comprometimento Organizacional dos Docentes no IFRN Campus Nova Cruz, 2017.

Fonte: Dados da pesquisa (2017).

As tabelas a seguir, descreveram a estatística descritiva de cada base quem compõe o EBACO, apresentando algumas características como média, modo, desvio padrão entre outros. 
A Tabela 10 irá apresenta dados referentes à Base Afetiva dos Docentes do IFRN Campus Nova Cruz no ano de 2017.

\section{Base Afetiva}

\begin{tabular}{|cc|}
\hline Média & 13,94 \\
\hline Erro padrão & 0,42 \\
\hline Modo & 17,74 \\
\hline Desvio padrão & 2,87 \\
\hline Variância & 8,27 \\
\hline Intervalo & 11,58 \\
\hline Mínimo & 6,9 \\
\hline Máximo & 18,48 \\
\hline Contagem & 46 \\
\hline
\end{tabular}

Tabela io - Estatística descritiva da Base Afetiva dos docentes.

Fonte: Dados da pesquisa (20I7).

A Base Afetiva obteve média de 13,94, classificada como acima da média, em contrapartida o desvio padrão foi de 2,87 e a variância de 8,27 foram altos, demonstrando respostas bastante diferentes, o erro padrão foi de 0,42 e o intervalo de 11,58, sendo o mínimo de 6,9 e o máximo de 18,48.

A Tabela 11 contém dados referentes à Base Obrigação em Permanecer dos Docentes do IFRN Campus Nova Cruz no ano de 2017.

\section{Base Obrigação em Permanecer}

\begin{tabular}{|cc|}
\hline Média & 10,00 \\
\hline Erro padrão & 0,74 \\
\hline Modo & 3,24 \\
\hline Desvio padrão & 5,04 \\
\hline Variância & 25,47 \\
\hline Intervalo & 15,42 \\
\hline Mínimo & 3,24 \\
\hline Máximo & 18,66 \\
\hline Contagem & 46 \\
\hline
\end{tabular}

Tabela II - Estatística descritiva da Base Obrigação em Permanecer dos docentes.

Fonte: Dados da pesquisa (2017).

A dimensão Obrigação em Permanecer apresentou média de 10 , erro padrão de 0,744 , modo 3,24, desvio padrão 5,04, variância da amostra 25,47, intervalo 15,42, mínimo de 3,24 e o máximo de 18,66 . 
A Tabela 12 se refere aos dados da Base Obrigação pelo Desempenho dos Docentes do IFRN Campus Nova Cruz no ano de 2017.

\section{Base Obrigação pelo Desempenho}

\begin{tabular}{|cc|}
\hline Média & 15,99 \\
\hline Erro padrăo & 0,27 \\
\hline Modo & 17,82 \\
\hline Desvio padrão & 1,84 \\
\hline Variância & 3,41 \\
\hline Intervalo & 6,59 \\
\hline Mínimo & 11,23 \\
\hline Máximo & 17,82 \\
\hline Contagem & 46 \\
\hline
\end{tabular}

Tabela I2 - Estatística descritiva da Base Obrigação pelo Desempenho dos docentes.

Fonte: Dados da pesquisa (2017).

A Dimensão Obrigação pelo Desempenho apresentou média de 15,99 com alto nível de comprometimento, seu erro padrão foi de 0,27 e o modo de 17,82. O desvio padrão baixo com 1,84, a variância alta de 3,41. O intervalo de 6,59 considerado baixo, com o mínimo de 11,23 e o máximo de 17,82 .

A Tabela 13 contém os dados estatísticos da Base Afiliativa dos Docentes do IFRN Campus Nova Cruz no ano de 2017.

\section{Base Afiliativa}

\begin{tabular}{|cc|}
\hline Média & 13,79 \\
\hline Erro padrão & 0,41 \\
\hline Modo & 14,9 \\
\hline Desvio padrão & 2,79 \\
\hline Variância & 7,79 \\
\hline Intervalo & 13,42 \\
\hline Mínimo & 4,46 \\
\hline Máximo & 17,88 \\
\hline Contagem & 46 \\
\hline
\end{tabular}

Tabela i3 - Estatística descritiva da Base Afiliativa dos docentes.

Fonte: Dados da pesquisa (2017).

Quanto à Base Afiliativa, sua média foi de 13,79, representando baixo comprometimento. O erro padrão de 0,41 e o modo 14,9. O desvio padrão e a variância desta base foram altos com 2,79 e 7,79 respectivamente, o intervalo de 13,42, sendo no mínimo 4,46 e no máximo 17,88. 
A Tabela 14 se refere aos dados estatísticos da Base Falta de Recompensas e Oportunidades dos Docentes do IFRN Campus Nova Cruz no ano de 2017.

Base Falta de Recompensas e Oportunidades

\begin{tabular}{|cc|}
\hline Média & 4,93 \\
\hline Erro padrão & 0,24 \\
\hline Modo & 2,54 \\
\hline Desvio padrão & 1,65 \\
\hline Variância & 2,72 \\
\hline Intervalo & 5,75 \\
\hline Mínimo & 2,54 \\
\hline Máximo & 8,29 \\
\hline Contagem & 46 \\
\hline
\end{tabular}

Tabela I4 - Estatística descritiva da Base Falta de Recompensas e Oportunidades dos docentes.

Fonte: Dados da pesquisa (2017).

A Tabela referente à Falta de Recompensas e Oportunidades mostra que essa Base apresentou média 4,93 classificada abaixo da média, com erro padrão de 0,24 e modo de 2,54. O desvio padrão 1,65, a variância 2,72 e o intervalo 5,75 considerado baixo com o mínimo de 2,54 e o máximo de 8,29.

A Tabela 15 apresenta os dados estatístico da Base linha Consistente de Atividades dos Docentes do IFRN Campus Nova Cruz no ano de 2017.

\section{Base Linha de Consistente de} Atividades

\begin{tabular}{|cc|}
\hline Média & 11,13 \\
\hline Erro padrão & 0,40 \\
\hline Modo & 10,52 \\
\hline Desvio padrão & 2,76 \\
\hline Variância & 7,61 \\
\hline Intervalo & 11,14 \\
\hline Mínimo & 4,64 \\
\hline Máximo & 15,78 \\
\hline Contagem & 46 \\
\hline
\end{tabular}

Tabela 15 - Estatística descritiva da Base Linha Consistente de Atividades dos docentes

Fonte: Dados da pesquisa (2017).

A Base Linha Consistente de Atividades obteve média de 11,13 que esta abaixo da média, sendo o erro padrão de 0,40 e o modo 10,52. O desvio padrão 2,76 e a variância de 7,61, o que demostra heterogeneidade nas respostas. O intervalo foi de 11,14 com o mínimo de 4,64 e o máximo de 15,78. 
A Tabela 16 apresenta os dados da Base Escassez de Alternativas dos Docentes do IFRN Campus Nova Cruz no ano de 2017.

\section{Base Escassez de Alternativas}

\begin{tabular}{|cc|}
\hline Média & 9,62 \\
\hline Erro padrão & 0,51 \\
\hline Modo & 5,34 \\
\hline Desvio padrão & 3,50 \\
\hline Variância & 12,31 \\
\hline Intervalo & 12,7 \\
\hline Mínimo & 2,98 \\
\hline Máximo & 15,68 \\
\hline Contagem & 46 \\
\hline
\end{tabular}

Tabela i6 - Estatística descritiva da Base Escassez de Alternativas dos docentes.

Fonte: Dados da pesquisa (2017).

A última Tabela desta seção a ser descrita e que apresentou o nível mais baixo de comprometimento da categoria a Base Escassez de Alternativas que alcançou média de 9,62. O desvio padrão e a variância altos, o erro padrão de 0,51 e o modo 5,34. O intervalo alto com 12,7, sendo o mínimo de 2,98 e máximo de 15,68 .

Em síntese, em relação ao comprometimento organizacional dos docentes, as Bases de comprometimento Obrigação pelo Desempenho apresentou um alto comprometimento com 93,5\% dos respondentes e a Base Afetiva 65\% dos docentes como nível acima da média. Em contrapartida, as Bases Obrigação em Permanecer e Escassez de Alternativas apresentaram os menores valores de comprometimento médio para os mesmos, com mais de $60 \%$ dos entrevistados apresentando baixo comprometimento. Resultados estes semelhantes aos de Envall, Teixeira, Envall e Dalongaro (2014).

\section{CONSIDERAÇÕES FINAIS}

Este artigo de curso teve como objetivo avaliar o nível de comprometimento organizacional dos servidores administrativos e docentes do IFRN Campus Nova Cruz à luz da Escala de Bases de Comprometimento Organizacional (EBACO). Diante do exposto, destaca-se que o objetivo foi alcançado.

Com base nos resultados da pesquisa, encontrou-se que as Bases de comprometimento Obrigação pelo Desempenho com 100\% dos entrevistados se encontram com alto comprometimento e a Afetiva, apresentou $80 \%$ com nível acima da média, sendo os maiores valores para a categoria de servidores Administrativos, em compensação as Bases Obrigação em Permanecer e Escassez de Alternativas apresentaram os menores valores de comprometimento médio para os mesmos com 50\%. Tais resultados podem ser explicados pela natureza do plano de cargos e pouca mobilidade de funções dentro da instituição, possibilitando uma sensação de estagnação e conformismo com a carreira percebida pelos servidores.

Já em relação ao comprometimento organizacional dos docentes, as Bases de comprometimento Obrigação pelo Desempenho apresentou um alto comprometimento com 93,5\% dos respondentes e a Base Afetiva 65\% dos docentes como nível acima da média. Em contrapartida, as Bases Obrigação 
em Permanecer e Escassez de Alternativas apresentaram os menores valores de comprometimento médio para os mesmos, com mais de $60 \%$ dos entrevistados apresentando baixo comprometimento. Tais resultados podem ser explicados pela natureza do plano de carreiras no funcionalismo público, que limita a atuação dos servidores.

Ao comparar as categorias pode-se perceber que ambas têm as Bases Obrigação pelo Desempenho e Afetiva com altos níveis de comprometimento, porém os servidores são visivelmente mais comprometidos que os docentes.

Como limitações da pesquisa, destaca-se o caráter instrumental do modelo EBACO, que permite uma abordagem geral da situação do comprometimento organizacional da organização, não gerando um aprofundamento em questões subjacentes ao comprometimento. Como estudos futuros, sugere-se aplicar o modelo EBACO em outros campi do IFRN para comparar os resultados e identificar se se trata de uma realidade local ou de toda a instituição.

Sugere-se do ponto de vista prático, a realização de ações que fomentem o comprometimento organizacional entre as categorias, especificamente ações voltadas às Bases Obrigação em Permanecer e Escassez de Alternativas, promovendo ações que permitam mobilidade de tarefas/cargos dentro da instituição.

\section{REFERÊNCIAS}

1. BASTOS, Antonio VB. Comprometimento no trabalho: a estrutura dos vínculos do trabalhador com a organização, a carreira e o sindicato. Comprometimento no trabalho: a estrutura dos vínculos do trabalhador com a organização, a carreira e o sindicato, 1994.

2. CANÇADO, Vera L.; GENELHU, Patrícia; DE MORAES, Lúcio Flávio Renault. Comprometimento com a profissão: um estudo em uma universidade no estado de Minas Gerais. Revista Eletrônica de Administração, v. 13, n. 1, p. 24-48, 2007.

3. CUNHA, Daniele Estivalete et al. confiança do empregado na organização e comprometimento organizacional: Em busca da relação em os construtos. Anais do Encontro da Associação Nacional de Pós-Graduação e Pesquisas em Administração, 2014.

4. ENVALL, M. F. O. et al. Comprometimento organizacional como uma variável estratégica da gestão de pessoas: Um estudo em uma empresa gaúcha. Anais do Encontro da Associação Nacional de Pós-Graduação e Pesquisas em Administração, 2014.

5. FANTON, Mariana Grapeggia et al. Comprometimento organizacional e qualidade do ensino: o caso da Faculdade de Ciências Sociais Aplicadas de Cascavel-PR. 2002.

6. GIL, Antonio Carlos. Métodos e técnicas de pesquisas social. 6. ed. 2. reimpr. São Paulo: Atlas, 2009.

7. INSTITUTO FEDERAL DO RIO GRANDE DO NORTE. Documento de apresentação 2017<http://portal.ifrn.edu.br/institucional> acessado em 31 de maio de 2017, ás 08:35. 
8. LAKATOS, Eva Maria; MARCONI, Marina de Andrade. Metodologia científica. 5. ed. 4. reimpr. São Paulo: Atlas, 2010.

9. LEITE, Nildes Raimunda Pitombo; ALBUQUERQUE, Lindolfo Galvão. Como gerir pessoas voltadas para o comprometimento em uma estrutura organizacional remota no alto sertão?. XXXVII Encontro da ANPAD. Rio de Janeiro, 2013.

10. MEDEIROS, Carlos Alberto Freire. (2003). Comprometimento Organizacional: o estado da arte da pesquisa no Brasil. Revista de Administração Contemporânea, 7(4), 187-209.

11. MELO, F. L. N. B. et al. Validação da escala de bases de comprometimento organizacional na gestão pública: Um estudo de caso no Tribunal de Contas do Estado do Rio Grande do Norte. Anais do Encontro da Associação Nacional de Pós-Graduação e Pesquisas em Administração, 2014.

12. PAIVA, Kely Cesar Martins; MORAIS, Marta Maria Santos. Comprometimento Organizacional: um estudo com docentes do CEFET-MG. Revista Gestão \& Tecnologia, v. 12, n. 1, p. 74-101, 2012.

13. PULINO, Sandra Aparecida Pagliaci; KUBO, E. K. M.; OLIVA, E. C. A geração Y e o seu comprometimento organizacional em empresas de conhecimento intensivo. Anais do Encontro da Associação Nacional de Pós-Graduação e Pesquisas em Administração, 2014.

14. REICHER, Ricardo; FONSECA, V. S. Comprometimento organizacional e comunicação interna como ferramenta estratégica: um estudo de caso. XXXVI Encontro da ANPAD. Rio de Janeiro, Set, 2012.

15. SANT'ANNA, D. A. et al. Avaliação do comprometimento e da cultura organizacional: Evidências do comprometimento de uma força de vendas autônoma em uma empresa do setor de condutores elétricos. Anais do Encontro da Associação Nacional de Pós-Graduação e Pesquisas em Administração, 2014.

16. TRALDI, Maria Teodora Farias; DEMO, Gisela. Comprometimento, bem-estar e satisfação dos professores de administração de uma universidade federal. Revista Eletrônica de Administração, v. 18, n. 2, p. 290-316, 2012. 